\title{
Delta Smelt (Hypomesus transpacificus) Exhibit Wide Variation in Spawning Behavior: An Investigation of Substrate Type, Diel Timing, and Participants
}

\author{
Yi-Jiun Jean Tsai ${ }^{1} \cdot$ Samantha Noel Chase $^{1} \cdot$ Evan W. Carson $^{2} \cdot$ Leanna Zweig $^{2} \cdot$ Tien-Chieh Hung $^{1}$ (I)
}

Received: 24 June 2021 / Revised: 4 November 2021 / Accepted: 8 November 2021 / Published online: 22 November 2021

This is a U.S. government work and not under copyright protection in the U.S.; foreign copyright protection may apply 2021

\begin{abstract}
Studies of cultured populations can be invaluable to the conservation of imperiled species for which little is known and whose very low abundance in the wild can preclude studies with robust sample sizes. For example, in endangered delta smelt (Hypomesus transpacificus), conservation measures developed to mitigate population decline are hindered by a lack of knowledge regarding spawning behavior. However, the availability of a cultured population allows important questions about spawning to be addressed experimentally. We examined the effect of substrate type on spawning behavior and egg fertilization success in cultured $H$. transpacificus under laboratory conditions. We also examined the diel frequency of spawning and the sex and number of spawning participants. We found that the frequency of spawns and resulting egg fertilization success did not differ between sand, gravel, and control (acrylic) substrates. We also demonstrated that spawning was predominantly nocturnal, though rare diurnal spawns were observed. Of the five mature males and five ripe females available within a given trial, spawns included up to seven participants, but most frequently occurred between a single female and one or two males. Our results highlight the wide behavioral variation exhibited by $H$. transpacificus during spawning, particularly in terms of substrate use, diel timing, and participants. These findings provide the most detailed and experimentally robust data regarding $H$. transpacificus spawning behavior to date and thereby provide ongoing conservation efforts with much-needed information.
\end{abstract}

Keywords Sex ratio $\cdot$ Conservation $\cdot$ Egg fertilization $\cdot$ Spawning attempt $\cdot$ Nocturnal

\section{Introduction}

To be most effective, conservation efforts require a thorough understanding of a species' life history and habitat requirements (Cooke et al. 2012). However, for many imperiled species, such knowledge is limited due to factors such as extremely low population size or logistically difficult sampling (Cooke et al. 2012). Thus, information pertaining to species biology and behavior may necessarily rely on

Communicated by Wim J. Kimmerer.

Tien-Chieh Hung

thung@ucdavis.edu

1 Fish Conservation and Culture Laboratory, Department of Biological and Agricultural Engineering, University of California, Davis, Davis, CA 95616, USA

2 US Fish and Wildlife Service, San Francisco Bay-Delta Fish and Wildlife Office, Sacramento, CA 95814, USA laboratory-based studies of cultured populations to augment what is known from field studies of wild populations.

One species for which laboratory experiments and studies of cultured populations are important is delta smelt (Hypomesus transpacificus), a small, pelagic fish endemic to the San Francisco Estuary (CA, USA). The wild $H$. transpacificus population has declined significantly in number, due in part to habitat alteration, invasive species, and altered hydrology (Moyle et al. 2016). As a result, H. transpacificus is listed as federally threatened (US Fish and Wildlife Service 1993) and state endangered (California Department of Fish and Game 2021). In addition, conservation measures have been developed to mitigate further population decline, which include proposed actions such as spawning habitat augmentation (California Natural Resources Agency 2016). However, such efforts have been hindered by the lack of knowledge regarding $H$. transpacificus spawning behavior. For example, neither eggs nor spawning behavior have been observed in the wild (Moyle et al. 1992, 2016; Bennett 2005), and little 
is known about the microhabitat requirements for $\mathrm{H}$. transpacificus spawning success.

Most $H$. transpacificus move from tidal fresh- and lowsalinity waters to spawn upstream in fresher waters of sloughs and rivers (Moyle 2002; Bennett 2005; Wang 2007; Merz et al. 2011; Sommer et al. 2011; Bennett and Burau 2015; Hobbs et al. 2019), though some may remain in brackishand freshwater as residents (Hobbs et al. 2019). They exhibit polygynandry (LaCava et al. 2015), can produce multiple egg clutches within a single spawning season (Damon et al. 2016), and primarily spawn in their first year, but can spawn at two years old (Moyle 2002; Lindberg et al. 2013; Damon et al. 2016). Although $H$. transpacificus has been cultured for conservation purposes since 1996 (Lindberg et al. 2013), their spawning behavior has only recently been characterized (Tsai et al. 2021a).

The current understanding of $H$. transpacificus spawning behavior is derived almost exclusively from laboratory studies of cultured and captive-held, wild-caught fish. Hypomesus transpacificus spawn by broadcasting demersal, adhesive eggs (Mager 1996; Moyle 2002) during fast, forward-swimming dashes while in direct contact with the substrate (Tsai et al. 2021a). They are thought to spawn predominantly at night, but evidence for this is either anecdotal (Mager 1996; Lindberg et al. 1997; Moyle 2002; Wang 2007) or based on a small sample size (Tsai et al. 2021a), so further testing is warranted. Both males and females can participate in multiple spawns within a clutch cycle and have been observed engaging in serial spawns within and across nights (Tsai et al. 2021a). The number of fish engaged in a given spawn ranges from 2 to 5 participants (out of 4 males and 4 females available; Tsai et al. 2021a), though the sexes of these participants is unknown. When provided a choice between varied spawning substrates and flow regimes, $H$. transpacificus deposit most eggs on sand and pebble under higher flow conditions, suggesting that these substrates and flow rates may be preferred among the choices tested (sand, pebble, cobble, artificial and natural Schoenoplectus acutus, dead wood, plastic control, and tank floor control at 1.4, 8.8 , and $15.4 \mathrm{~cm} / \mathrm{s}$; Lindberg et al. 2020). However, it is unclear whether $H$. transpacificus require specific substrates to reproduce successfully. Thus, while recent papers have greatly advanced our understanding of $H$. transpacificus spawning, much remains unknown about their basic reproductive needs and variability in spawning behavior.

We examined the effect of substrate type on spawning behavior and egg fertilization success, as well as described behavioral characteristics of spawning in cultured $H$. transpacificus. We asked, what is the effect of substrate type on the frequency of spawning behaviors and on egg fertilization success when no choice between substrates is provided? We also asked the following: (1) what is the diel frequency of spawning, (2) what is the duration of spawning behaviors,
(3) where does spawning occur within the water column, (4) in what direction of flow does spawning occur, and (5) what is the sex and number of participants engaged in a given spawning event?

\section{Methods}

We conducted 18 spawning trials from February 20 to May 4, 2020. For each trial, five mature males and five ripe females were introduced into a tank containing sand, gravel, or control (acrylic) substrate and allowed to interact freely for 4 days. Fish were video recorded for the duration of the trial, and videos were later analyzed for spawning behavior. Eggs laid during the trial were incubated for three additional days and then assessed for fertilization success.

\section{Fish}

Experimental fish were 1-year-old, cultured $\left(\mathrm{F}_{12}\right) \mathrm{H}$. transpacificus maintained in freshwater at the UC Davis Fish Conservation and Culture Laboratory (Byron, CA; Lindberg et al. 2013). These fish were selected from tanks containing excess production fish from the refuge population cultured at the facility (Lindberg et al. 2013). The multi-family groups from which they were derived had domestication indices (a measure of hatchery ancestry) ranging from 6.2 to 9.5 (Finger et al. 2018).

To select sexually mature fish, we gently squeezed the abdomen near the vent of each individual and observed whether gametes were expressed (Lindberg et al. 2013). We selected mature males based on milt expression and ripe females based on body condition, egg expression, and egg maturity (Tsai et al. 2021a). To visually differentiate between males and females during video analysis, one sex within each trial received an upper-caudal fin clip. The sex to be fin-clipped was randomly selected prior to each trial, ensuring that both sexes were equally represented across all trials.

When fish were introduced into the tank, they were initially monitored for approximately $1-2 \mathrm{~h}$. Any fish that exhibited extreme stress response (lying on the tank bottom) and did not begin to swim normally within this period was removed and replaced with another fish of the same sex. Across all trials, three fish were replaced due to stress. The trial began after all human disturbance ceased.

Fish health was monitored daily. Mortalities were immediately removed upon observation. Of 180 total fish used, two (1\%) died and were removed during the experiment. To minimize disturbance, fish were not fed during the trial. All protocols regarding fish handling and care followed UC Davis Institutional Animal Care and Use Committee requirements. 
Fish were not tagged, so we could not determine whether individuals were re-used in later trials. However, the number of individuals used more than once was likely low. Fish were drawn from a tank containing a large number of fish (approx. 1300-3000 fish), which fluctuated with incoming fish and mortalities throughout the study. Females of a given trial would become unsuitable for use in future trials if they did not spawn, as ripe females that hold their eggs become overripe in approximately 3 days. For females that did spawn, only those used in trials at the beginning of the study had sufficient time to develop a second clutch by the end of the study (refractory period between clutches is approx. 40-60 days; Hung et al. 2019; Tran et al. 2019).

\section{Experimental Spawning Systems}

Fish were placed into a $43.8-\mathrm{cm} \mathrm{W} \times 58.4-\mathrm{cm} \mathrm{L} \times 30.5$ $\mathrm{cm} \mathrm{H}$ (78-L) compartment within a $284-\mathrm{L}$, clear acrylic, flow-through tank (Figures S1-3, Online Resource 1). The compartment was enclosed with $0.6-\mathrm{cm}$ plastic mesh. Tank inflow was provided by a $40.6-\mathrm{cm}$-long, $2.5-\mathrm{cm}$-diameter spray bar set $14.6 \mathrm{~cm}$ above the tank bottom. Tank outflow overflowed into a 3.8-cm-diameter standpipe. Both in- and outflows were located outside of the compartment and were not accessible to fish. Outflow emptied into a 206-L sump, from which inflow was pumped. Water volume of the entire system was approximately $323 \mathrm{~L}$ (see Online Resource 1 for more details). A sock filter and synthetic filter resin (Purigen, Seachem Laboratories, GA, USA) were placed at the terminus of outflow to filter out-flowing eggs, aid in debris and waste removal, and minimize water turbidity. The tank, sump, and tank equipment were disinfected with $355 \mathrm{ppt}$ salt water and then thoroughly rinsed with freshwater between trials. Two independent spawning tank systems were constructed and allowed for two trials to run concurrently.

\section{Video Recording Setup}

A video camera (RLC-511, Reolink, DE, USA) with infrared capability centered on the side of the compartment captured all behavioral interactions. A black backdrop was placed behind the tank to increase contrast between fish and the background during filming. The entire tank-sump-camera system was housed within black plastic to control lighting conditions and minimize visual disturbance.

\section{Water and Light Conditions}

Water for this experiment was surface freshwater pumped from the California Aqueduct, just south of Clifton Court Forebay (Contra Costa County, California; Lindberg et al. 2013). Starting 7 days before each trial, water was filtered
( $1 \mu \mathrm{m}$ canister filter) continuously to minimize turbidity. Water was maintained at $12.1 \pm 0.005{ }^{\circ} \mathrm{C}$. Water quality (salinity, $\mathrm{pH}$, dissolved oxygen, total ammonia nitrogen, nitrate, and nitrite) was monitored according to facility maintenance standards (Tigan et al. 2020). Incoming water flow was set to $15 \mathrm{~cm} / \mathrm{s}$ (Flo-Mate 2000 portable flow meter, Marsh-McBirney, Inc., MD, USA), measured at the upstream end of the compartment.

We provided visible light (15:9 h day:night cycle; AquaAir 1200, MicMol, Guangdong, China) during the day, with light intensity gradually increasing and decreasing to mimic the daily natural photoperiod (Figure S4; Online Resource 1). We also provided infrared lighting (80 ft IR Illuminator, Tendelux Technology, Guangdong, China) at night (no visible light from 20:40 to 05:50) to allow for nighttime video recording.

\section{Substrate}

For each trial, one of three substrates was provided: sand, gravel, or control (acrylic). As H. transpacificus eggs are naturally adhesive, we constructed panels (black acrylic, $14.6 \mathrm{~cm} \mathrm{~L} \times 14.6 \mathrm{~cm} \mathrm{~W} \times 0.32 \mathrm{~cm} \mathrm{H}$ ) containing substrate that could be incubated after the behavioral trial with minimal disturbance to the eggs. The tank bottom was created using a $3 \times 4$ matrix of substrate panels that covered the entirety of the observation compartment (Figure S2, Online Resource 1). Sand and gravel were chosen based on studies by Lindberg et al. (2020) and Tsai et al. (2021a), in which fish spawned successfully on similar substrates. For these substrates, sand (black aquarium sand, $19.7 \%>1 \mathrm{~mm}$, 79.0\% 0.5-1 mm, and 1.3\% 0.25-0.5 mm; Merkus 2009) or gravel (black aquarium gravel, mean size of $16.2 \mathrm{~mm} \mathrm{~L}$ $\times 11.0 \mathrm{~mm} \mathrm{~W} \times 5.7 \mathrm{~mm} \mathrm{H}$ ) was glued onto black, sanded acrylic panels using clear silicone, dried for at least 1 day, and then leached for 3 days prior to use. For the control substrate, black acrylic panels were sanded to provide a slightly textured surface onto which eggs could adhere. All substrates were black to minimize fish stress (BaskervilleBridges et al. 2005). The testing order of substrate type was randomized, ensuring that substrate types were distributed between both tank systems and across time.

\section{Behavior Definitions}

Videos were observed at up to $2 \times$ speed for the first $24 \mathrm{~h}$ of each trial. We recorded two spawning-related behaviors: spawns and attempts, as defined by Tsai et al. (2021a). Spawns were fast, synchronous, forward-swimming dashes (bouts) between multiple fish swimming in tandem and in close proximity to one another (usually touching and sideby-side) that included egg release. Attempts were fast, synchronous, forward-swimming dashes, but without egg 
release. Multiple bouts could comprise a single interaction. For spawns, egg release could occur at any time and more than once. During a given spawn or attempt, individuals could join or leave the interaction at any point. Whereas Tsai et al. (2021a) excluded attempts in which fish were not directly side-by-side one another, we counted attempts in which fish engaged in bouts directly side-by-side or atop one another. The beginning of a spawn or attempt was defined as when fish started their first bout. The end of a spawn or attempt was defined as when all participants separated or turned away from one another and did not immediately $(\leq 1 \mathrm{~s})$ re-engage in further spawning behavior. Due to high water clarity and bright infrared lighting, egg release was highly visible and thus unlikely to be missed. In rare cases where egg release was ambiguous, we conservatively categorized the behaviors as attempts.

Sometimes, behaviors were interrupted or hindered by the walls of the tank compartment, in which fish either made physical contact with or stopped just short of reaching a compartment wall (within $1 / 2$ fish length) during a spawn or attempt. We therefore recorded whether or not each spawn or attempt was "impeded" (referred to as "completed" behaviors in Tsai et al. 2021a). Impeded attempts encompassed a degree of uncertainty regarding whether the attempts would have become spawns had they not been interrupted. For impeded spawns, egg release occurred prior to or despite the interruption. For example, in some cases, fish swam in one direction, were redirected to another direction by the compartment wall, and then released eggs. In other instances, fish swam directly into a wall or compartment corner and released eggs while continuing to swim into the barrier. The impeded status of spawns and attempts was considered in analyses of duration and direction.

\section{Egg Incubation and Quantification}

At the end of each trial, substrate panels were transferred from the experimental compartment to an egg incubation chamber and incubated for 3 days. Egg incubation chambers were $22-\mathrm{L}$ plastic bins measuring approximately $48.9 \mathrm{~cm}$ $\mathrm{L} \times 28.6 \mathrm{~cm} \mathrm{~W} \times 19.1 \mathrm{~cm} \mathrm{H}$ (Figures S5-8, Online Resource 1). Water was maintained at a depth of $15.2 \mathrm{~cm}$ (20-L water volume). Inflow (approx. $5 \mathrm{~cm} / \mathrm{s}$ ) was provided by a $1.3-\mathrm{cm}$ diameter spray bar connected to a pump. Outflow was a 22.5$\mathrm{cm} \mathrm{L} \times 2.5-\mathrm{cm} \mathrm{H}$ cutout covered in $350 \mu \mathrm{m}$ mesh to prevent eggs from exiting the chamber. Panels were placed upright into slots in a single row directly in front of inflow, which maximized flow across panels and minimized the spread of any fungal growth between panels. Two egg incubation chambers (one for each of the two trials run concurrently) were contained within a $170-\mathrm{L}$ plastic tub and shared the same water (see Online Resource 1 for more details). Water volume of the entire system was approximately $103 \mathrm{~L}$. Water was maintained at $12.6 \pm 0.009{ }^{\circ} \mathrm{C}$ and filtered continuously.

Eggs attached to substrate panels represented a subset of the total eggs laid and were the only eggs used to estimate egg fertilization success, with one exception. In one control trial, eggs did not adhere well to the panels for unknown reasons. In this case, loose eggs aggregated within the tank were collected and suspended within the egg incubation chamber to incubate in conjunction with substrate panels. Examination of the resulting data suggest that incubating loose eggs did not impact the estimated egg fertilization rate in this trial.

After incubating for 3 days, eggs were removed from substrate panels, counted, and categorized following protocols described in Tsai et al. (2021b). To detach eggs, panels were placed in a bath of diluted sodium hypochlorite solution $(0.13 \%)$ and agitated for approximately $3 \mathrm{~min}$. As the sodium hypochlorite solution was not always sufficient to fully detach all eggs within 3 min, we also detached eggs by gently brushing them with a soft-bristle paintbrush or spraying them with sodium hypochlorite solution from a 7.7- $\mathrm{mL}$ transfer pipette during the bath. After the bath, each panel was inspected to ensure that all eggs had been removed. Eggs were then filtered through a 350- $\mu \mathrm{m}$ mesh screen and rinsed with freshwater. Detached eggs were assembled in a single-layer within a small bowl and photographed in batches. From the resulting photographs, eggs were counted and categorized as either fertilized or dead (Tsai et al. 2021b) using ImageJ (Schneider et al. 2012) with Fiji extension (Schindelin et al. 2012). After egg detachment, substrate panels were rinsed with freshwater, scrubbed with a toothbrush, soaked in bleach neutralizer (Prime water conditioner, Seachem Laboratories, Madison, GA), and then rinsed thoroughly with freshwater again before re-use.

\section{Behavior and Egg Fertilization Analyses}

All statistical analyses were conducted using $\mathrm{R}$ version 3.5.1 (R Core Team 2018) and RStudio version 1.1.456 (RStudio Team 2018). Figures were created in SigmaPlot 14.0 (Systat Software, San Jose, CA).

To examine the effect of substrate type on the total number of spawns and attempts, we used linear regression models in which substrate type was the explanatory variable, date was a covariate, and the number of spawns or attempts was the response variable (car package; Fox and Weisberg 2019). For spawns, date was not a significant factor $(P>0.05)$, so it was dropped from the model. The resulting ANOVA showed heterogenous variances, so a Welch's heteroscedastic $F$-test was used instead (onewaytests package; Dag et al. 2018). For attempts, date was a significant factor and therefore remained in the model. 
To examine the effect of substrate type on the total number of eggs counted, we used a generalized linear model with a Poisson distribution, in which the total number of eggs was the response variable, substrate type was the explanatory variable, and date was a covariate. This model was overdispersed, so we fit one with a negative binomial distribution instead (glm.nb, MASS package; Venables and Ripley 2002), which was not overdispersed. Date was not a significant factor (likelihood ratio test, $P>0.05$ ), so it was dropped from the final model.

To examine the effect of substrate type on egg fertilization success, we used a generalized linear model with a binomial distribution, in which the proportion of eggs fertilized was the response variable (weighted by the total number of eggs), substrate type was an explanatory variable, and date was a covariate. This model was overdispersed, which we addressed in two separate ways. First, we added an observation-level random effects term to our model (Harrison et al. 2015), which resulted in a generalized linear mixed-effects model with a binomial distribution (lme4 package; Bates et al. 2015) that was not overdispersed. Second, we fit a quasi-binomial generalized linear model (family = quasibinomial) to the data. The results of the mixed-effects and quasi-binomial models were the same, so we reported only results from the first. Again, date was not a significant factor (likelihood ratio test, $P>0.05$ ), so it was dropped from the final model.

In addition to the effects of substrate, we also examined spawns and attempts in terms of location within the water column, diel frequency, duration, direction in relationship to flow, and number and sex of participants. For these analyses, spawning behaviors were pooled across all substrates (see "Results"). For location, the number of spawns and attempts that occurred in either the top or bottom half of the water column was recorded. To examine the diel frequency of spawns and attempts, we focused at night when most spawning behavior occurred (see "Results"). We divided the time of night (20:40-05:50) into ten 55-min bins and examined the mean frequency of spawns and attempts across all trials per bin. To examine the duration of spawning behaviors, we compared the duration of spawns to that of attempts using a $t$-test accounting for unequal variances. We also compared the duration of male-female attempts to male-only attempts using a two-sample $t$-test. Only unimpeded behaviors were included in analyses of duration. For direction, we quantified the number of spawns and attempts that occurred with, against, or perpendicular to flow, using only uni-directional and unimpeded behaviors. To examine the number and sex of participants, we created a histogram of spawns and attempts grouped based on unique combinations of female and male participants (e.g., 1 female- 1 male, 2 females- 1 male, 2 females- 2 males). The number of participants was determined using the maximum number of different individuals that engaged in a single spawn or attempt at any time, regardless of whether they participated simultaneously (Tsai et al. 2021a). The sex of participants was identified on video using fin clips.

\section{Results}

Of 18 trials conducted, 17 were assessed for spawning behavior. One sand trial was excluded from behavioral analyses due to high water turbidity, which obscured observations of egg releases. Of 17 trials in which spawning behavior could be assessed, 631 spawns and 433 attempts were observed in the first $24 \mathrm{~h}$ of: 5 of 6 control, 5 of 5 sand, and 4 of 6 gravel trials ( 409.6 total hours of video). There were no obvious differences in the expression (sequence and visible manner in which behaviors were exhibited) of spawning behaviors that occurred on the different substrate types (Online Resources 2-4). Substrate type did not significantly affect the number of spawns (Welch's heteroscedastic $F$-test, $N=17, F_{2,7.7}=0.88, P=0.45$ ) or attempts (linear regression model, $\left.F_{2,13}=1.21, P=0.33\right)$ when controlling for date $\left(F_{1,13}=5.73, P=0.03\right.$; Fig. 1$)$.

Eggs were successfully fertilized in all 18 trials. Substrate type did not significantly affect the total number of eggs counted (generalized linear model, $N=18, X_{2}{ }_{2}=2.31$, $P=0.32$ ) or the proportion of eggs fertilized (generalized linear mixed-effects model, $N=18, X^{2}{ }_{2}=0.93, P=0.63$; Fig. 2). Across all substrates, the mean $\pm S E$ number of eggs counted was $5579.3 \pm 518.8$ eggs (range $=2210-9180$ eggs), and the mean $\pm S E$ proportion of eggs fertilized was $0.46 \pm 0.05$ (range $=0.11-0.79)$.

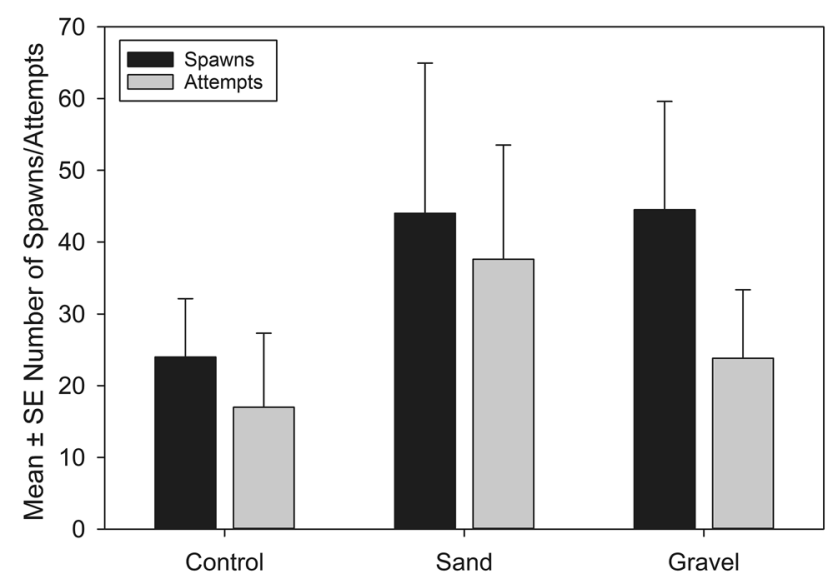

Fig. 1 The mean $\pm S E$ number of spawns and attempts by substrate type. Black bars indicate the mean number of spawns. Gray bars indicate the mean number of attempts. There were no significant differences $(P>0.05)$ in the number of spawns or attempts exhibited between control $(N=6$ trials), sand $(N=5)$, and gravel substrates $(N=6)$ 


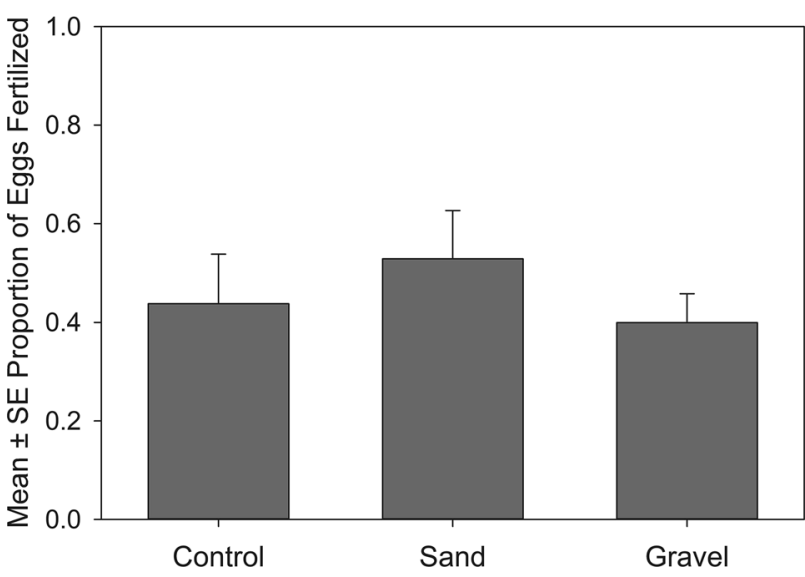

Fig. 2 The mean $\pm S E$ proportion of eggs fertilized by substrate type. There were no significant differences $(P>0.05)$ in the proportion of eggs fertilized between control $(N=6$ trials), sand $(N=6)$, and gravel substrates $(N=6)$

All 631 spawns and 433 attempts occurred at the bottom of the water column, directly on the substrate. Of these, 597 (94.6\%) spawns and 421 (97.2\%) attempts occurred at night. When we examined the mean number of nighttime spawns and attempts per 55-min bins, we found that nocturnal spawning behavior was most frequent at the beginning and end of night (Fig. 3), though the distribution of spawns and attempts varied by trial (Figure S9, Online Resource 1). The mean $\pm S E$ number of nighttime behaviors per 55-min bin was $3.5 \pm 0.5$ spawns/55-min (range $=0-40$ ) and $2.5 \pm 0.4$ attempts/55min (range $=0-46$ ). Daytime spawns and attempts were only observed in one trial (Online Resource 5). When we examined this trial further, we found no obvious pattern to the distribution of diurnal spawns (Fig. 4). In this trial, day spawns comprised $37.0 \%$ of 92 total spawns and $20.0 \%$ of 60 total attempts.
Spawning behavior was unimpeded (without interference from compartment walls) in 239 (37.9\%) of 631 spawns and $253(58.4 \%)$ of 433 attempts. The mean $\pm S E$ duration of these unimpeded spawns and attempts was $3.23 \pm 0.22 \mathrm{~s}$ (range $=1-37$ ) and $2.43 \pm 0.12 \mathrm{~s}$ (range $=1-9$ ), respectively. Unimpeded spawns were significantly longer in duration than unimpeded attempts (Welch's two-tailed $T$-test, $\left.t_{361.93}=-3.25, P=0.001\right)$. Male-only attempts $(N=161)$ and male-female attempts $(N=88)$ were not significantly different in duration (two-sample T-test, $t_{247}=1.55$, $P=0.122$ ).

Of 234 uni-directional, unimpeded spawns that were assessed, $94.9 \%$ occurred against flow, $2.6 \%$ with flow, and $2.6 \%$ perpendicular to flow. Of 247 uni-directional, unimpeded attempts that were assessed, $97.9 \%$ occurred against flow, $1.6 \%$ with flow, and $0.4 \%$ perpendicular to flow.

The number of participants engaged in a given spawn or attempt ranged from two to seven (Fig. 5). Most spawns occurred between one female and one male $(57.6 \%$ of 627 spawns in which the sex and number of participants could be determined) or one female and two males (25.1\%). Most attempts occurred between two males (55.2\% of 424 attempts in which the sex and number of participants could be determined) or between one female and one male $(24.1 \%)$.

\section{Discussion}

We found that substrate type did not affect the expression of spawning behavior, the frequency of spawning behaviors, or egg fertilization success. We also found that spawning occurred predominantly at night, with diurnal spawns occurring rarely. Furthermore, spawns most often occurred between a single female and one or two males, but could
Fig. 3 The mean $\pm S E$ number of nocturnal spawns and attempts by time. The time of night (20:40-05:50) was divided into ten 55-min bins. The start time of each bin is labeled on the $x$-axis. Black bars indicate the mean number of spawns ( $N=17$ trials). Gray bars indicate the mean number of attempts

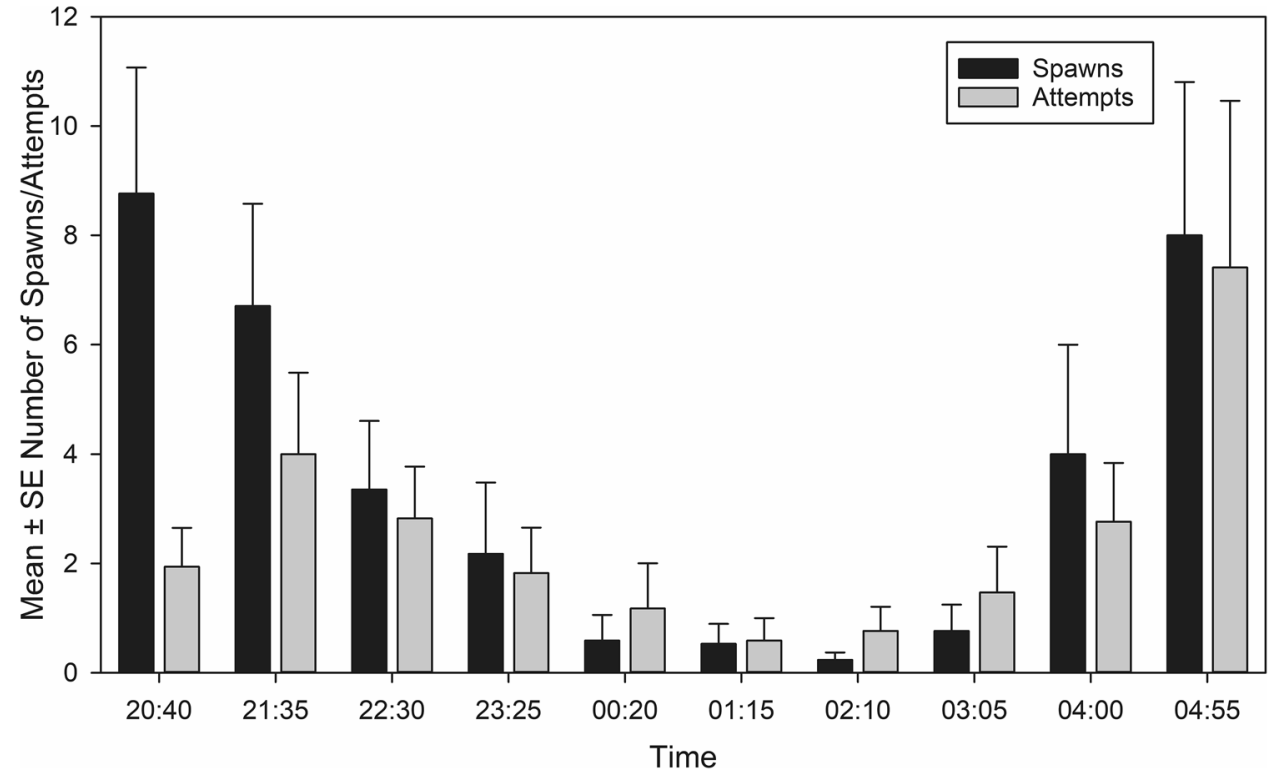




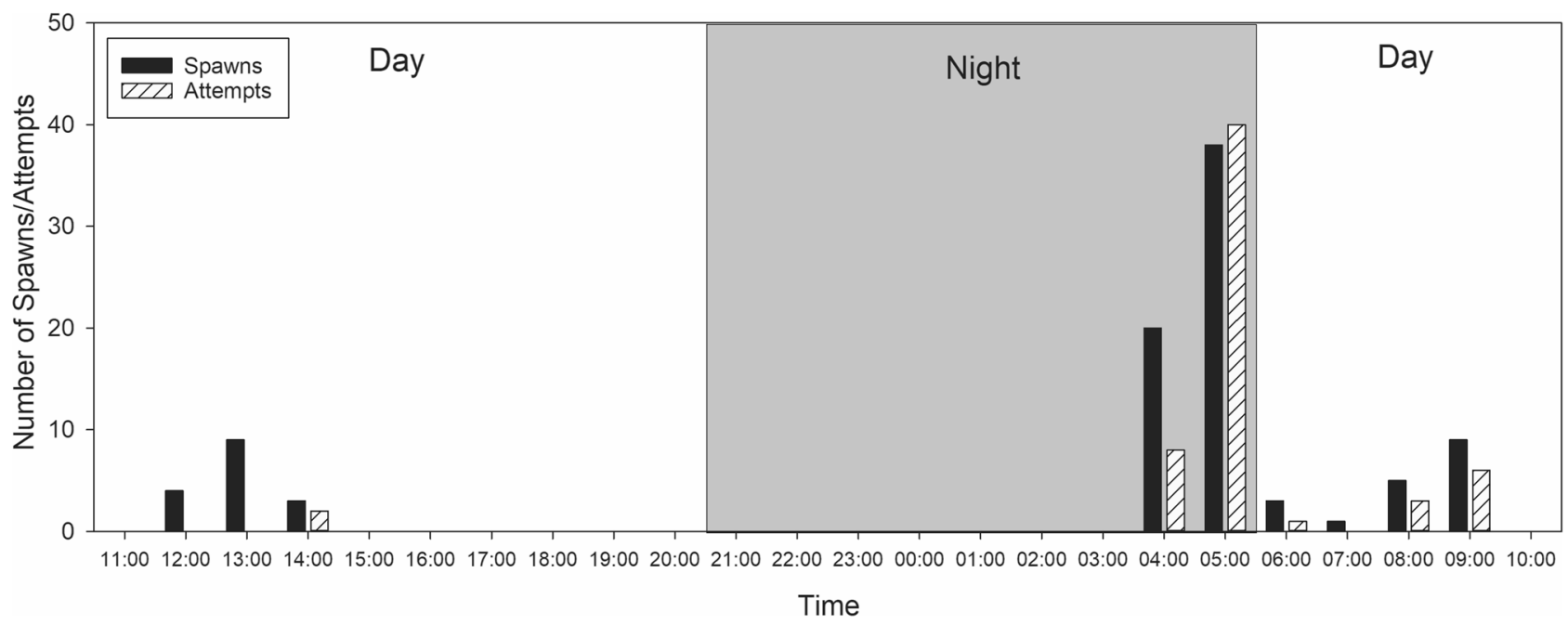

Fig. 4 The number of spawns and attempts by time for the only trial in which diurnal spawning behavior was observed. The start time of each hourly bin is labeled on the $x$-axis. Black bars indicate the number of spawns. Gray, hatched bars indicate the number of attempts.

include up to seven participants under the conditions tested here. These results pertain specifically to cultured

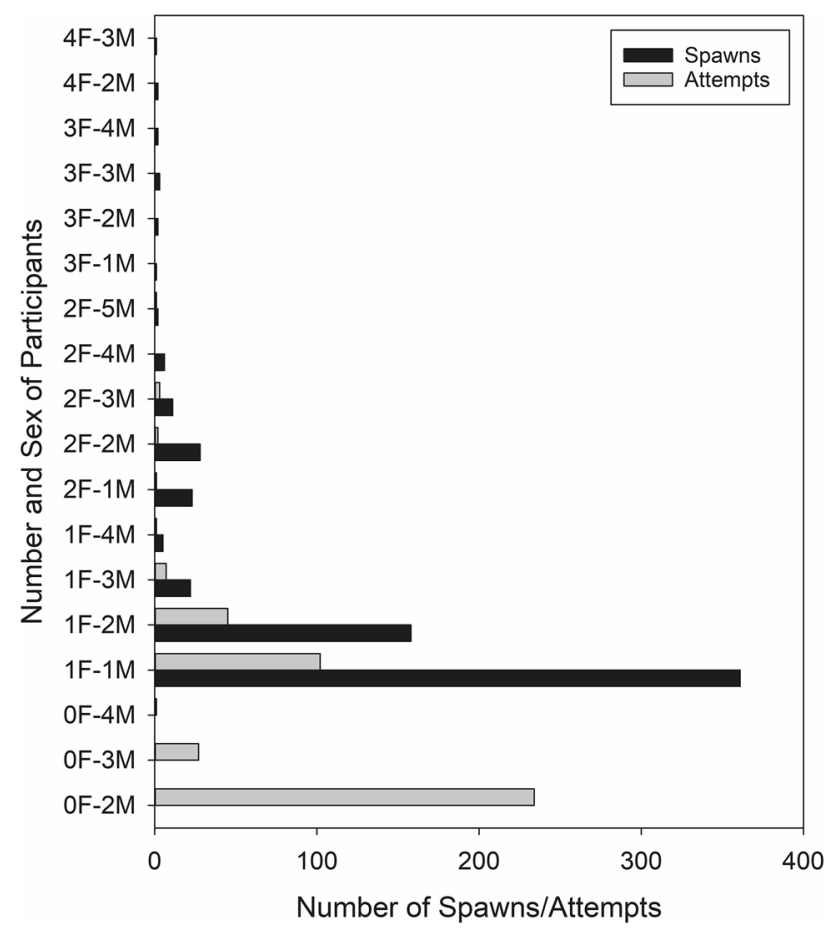

Fig. 5 The number and sex of participants in spawns and attempts ( $N=17$ trials). On the $y$-axis, the number of female participants is followed by F, the number of males is followed by M, and a dash separates the number of each sex. Sex ratios are listed from bottom to top in increasing order of the number of female participants, followed by increasing number of male participants. Black bars indicate the number of spawns. Gray bars indicate the number of attempts. A total of 629 spawns and 424 attempts were observed in which the sex and number of participants could be determined
Dark gray area of the graph indicates night (20:40-05:50), when no visible light (only infrared) was provided. Day was when visible light was provided. Behavior was only analyzed for the first $24 \mathrm{~h}$ of the trial and began at 10:58

H. transpacificus under laboratory settings, yet provide life history information that could improve the management of this imperiled species.

Using an experimental design in which fish were exposed to only one substrate type at a time allowed us to demonstrate that cultured $H$. transpacificus can utilize many different spawning substrate types, regardless of substrate preference (e.g., Lindberg et al. 2020) and assuming that other spawning requirements are met. Our findings also suggest that substrate type is not an important cue to either triggering the onset of spawning behavior or determining the frequency of spawning behaviors, though it may be important to other aspects of spawning or life history, such as spawning site selection (e.g., Lindberg et al. 2020) and offspring survival. The willingness to spawn on varied substrate types may also exist in the wild population, as preliminary studies of wildcaught $H$. transpacificus show that they also spawn naturally on acrylic substrate in laboratory experiments when no choice is allowed (Y.-J. J. Tsai, personal observation). Instead, other factors, such as flow (Lindberg et al. 2020) or tidal cycle (Bennett 2005), may have a greater effect on spawning behavior and warrant further study.

Among osmerids, the diel periodicity of spawning is varied, with some species reportedly spawning during the day (e.g., Pacific surf smelt $H$. pretiosus in Puget Sound, USA; Loosanoff 1938), and others spawning just after dusk or dark (e.g., Wakasagi H. nipponensis in Lake Kawaguchiko, Japan; Okazaki et al. 2011 and Japanese Surf Smelt H. pretiosus japonicus in Otsuchi Bay, Japan; Hirose and Kawaguchi 1998) or at night (e.g., H. nipponensis in Lake Nojiri, Japan; Peterson et al. 2021). In H. transpacificus, a study by Tsai et al. (2021a) and several anecdotal 
observations (Mager 1996; Lindberg et al. 1997; Moyle 2002; Wang 2007) indicated that spawning is nocturnal. Our study not only confirms the predominance of nocturnal spawning within the cultured $H$. transpacificus population, but also illustrates wide variation in the timing of spawning across trials (Figure S9, Online Resource 1). Furthermore, we documented the first observation of diurnal spawning in this species, as far as we are aware. In 1 of 17 behavioral trials, fish exhibited both diurnal and nocturnal spawning, with $37 \%$ of 92 spawns and $20 \%$ of 60 attempts occurring during visible light hours. We suggest that the observed diurnal spawns are representative of what may occur naturally, as there was no obvious experimental reason that explained the onset and number of diurnal spawns recorded throughout the day. Diurnal spawning has also been observed in subsequent laboratory studies of wild-caught $H$. transpacificus (Y.-J. J. Tsai, personal observation), though these data are not yet published. Thus, the diel periodicity of spawning in $H$. transpacificus appears to be predominantly nocturnal, but with wide variation in timing and frequency.

We differentiated between spawning behaviors that did and did not result in egg release. Making this distinction was important, as spawns are an indication of potentially successful reproduction, whereas attempts are an indication of unsuccessful effort. The ability to control egg release may be one way in which females can exert mate choice (e.g., Berejikian et al. 2000), in addition to possible postcopulatory mechanisms (e.g., Auld et al. 2019). As we could not determine whether males released milt during a given spawn or attempt, we could not assess male effort or response. However, the high frequency of male-only attempts observed suggests that males may not be choosy, may be willing to expend energy engaging in unsuccessful interactions, or both. During these male-only attempts, it appeared that males were triggered by the fast, forward swimming of fish around them, without regard for the sex(es) of their partner(s). It is possible that the energetic cost for males to engage in unsuccessful spawning behavior is low relative to the cost of a missed mating opportunity. In contrast to the high number of male-only attempts, we did not observe any female-only attempts and noted only two instances in which females released eggs in conjunction with spawning behavior (fast, forward dash), but without the explicit participation of any other fish (Online Resource 6). Hence, females appear to be less likely to engage in spawning interactions with no chance of reproductive success. Alternatively, male-only attempts may be a form of mate competition or competitor assessment, which would also explain the lack of female-only attempts. However, maleonly attempts were neither visually distinctive nor different in duration than male-female attempts, and no obvious territorial, contest, or display behaviors were observed among males in this study. Together, these observations suggest that, if mate competition occurs under the conditions tested, it is subtle. Studies in which individual identities can be distinguished and that test potential male competitor traits (e.g., body size; Auld et al. 2019) may help determine whether male-only attempts are the result of unsuccessful spawning effort or a form of mate competition.

While we did not observe any visually obvious behavioral differences between spawns and attempts, spawns were longer in duration. Though, it was not clear whether prolonged interactions were more likely to lead to egg release or whether egg release led to prolonged interactions; egg release could occur at any time and more than once during a single interaction. However, our measure of duration was likely biased towards shorter interactions, as the size of the experimental compartment limited the number of unimpeded behaviors that occurred; only $37.9 \%$ of 631 spawns and $58.4 \%$ of 433 attempts were unhindered by compartment walls. Studies utilizing larger compartments may be necessary to more fully quantify these $H$. transpacificus spawning behaviors. Interestingly, male-only attempts were not different in duration than male-female attempts, suggesting that attempts were terminated quickly, regardless of sex. Thus, the cues that determine mating or competition success may be assessed by participants early in the behavioral process.

Though there was the potential for mass broadcast spawning amongst multiple partners within a single interaction, mating in single-female pairs or small groups was more common. Therefore, as suggested in Tsai et al. (2021a), the high variation in reproductive success observed among both males and females in LaCava et al. (2015) is likely explained by individuals spawning repeatedly across many separate interactions. Such serial spawning was highlighted in this study by the high rate of spawns measured (up to 40 times within a 55-min period), as well as some opportunistic observations of the same individuals participating in multiple spawns in rapid succession. Our findings are similar to what has been reported in other wild osmerids, including $\mathrm{H}$. pretiosus japonicus of Otsuchi Bay, Japan (Hirose and Kawaguchi 1998) and $H$. pretiosus of Puget Sound, USA (Loosanoff 1938), where spawners congregate in large aggregations before breaking off to spawn in smaller groups consisting of a single female and a variable number of males. In $H$. transpacificus, additional studies examining spawning across a range of social conditions are needed to determine whether these trends persist and to understand how these dynamics may change depending on sex ratio and group size.

We used cultured $H$. transpacificus to examine spawning behavior, as a sufficient number of wild-caught $H$. transpacificus could not be obtained for this study. Accordingly, we caution that the behaviors observed here may differ from those in wild H. transpacificus. Indeed, morphological, life history, and behavioral differences between cultured 
(including hatchery-reared, captive-reared, farmed, etc.) and wild populations are well documented in some model species (e.g., salmonids; Fleming et al. 1996; Jonsson and Jonsson 2006). Nevertheless, studies of cultured populations can provide important insight into how wild populations might behave, and there can be similarities or retained behavioral traits between the two. For instance, in Atlantic Salmon Salmo salar of Norway, similarities in spawning behavior are presumably sufficient to allow for escaped farmed females to spawn successfully with wild males (Lura and Sægrov 1991). In the case of H. transpacificus, preliminary studies suggest that wild-caught and cultured $H$. transpacificus willingly spawn with one another under laboratory conditions (Y.-J. J. Tsai, personal observation). Furthermore, although spawning behavior in osmerids is not well-studied, that of cultured $H$. transpacificus fit with what is known about spawning in wild populations of closely related species. In H. pretiosus japonicus of Otsuchi Bay, Japan, fish aggregate offshore soon after sunset and engage in fast dashes towards the shoreline just after dark (Hirose and Kawaguchi 1998). In H. pretiosus of Puget Sound, USA, spawning occurs when fish swim fast toward shore and release their gametes onto sandy beaches in shallow water (Loosanoff 1938). Thus, although studies of wild $H$. transpacificus are ideal, research examining cultured fish provides valuable data that can inform the management of the species, especially when considering the imminent release of genetically-managed, cultured $H$. transpacificus into the wild for supplementation purposes (USFWS 2019).

Our study is one of few to examine spawning behavior in $H$. transpacificus and was conducted using one of the more robust experimental designs to date. We demonstrate that $H$. transpacificus exhibit far more variation in spawning behavior than previously understood, particularly in their ability to spawn on different substrate types, throughout the day, and with participants that vary in number and sex. Furthermore, our study illustrates that the $H$. transpacificus mating system is complex and warrants further study to characterize the behavioral diversity of this critically endangered species.

Supplementary Information The online version contains supplementary material available at https://doi.org/10.1007/s12237-021-01030-0.

Acknowledgements We gratefully thank the Fish Conservation and Culture Laboratory staff, especially Dr. W. Mulvaney and M. Rhodes, for their help in experimental design, system construction, fish care, and experiment maintenance. We also thank F. Putri and L. Tavares for aid in sand particle analysis and Dr. T. Kurobe for aid in journal article language translation.

Funding This study was supported by the US Fish and Wildlife Service (No. F18AC00075).

\section{Declarations}

Research Involving Human and Animal Participants Animal work was conducted in compliance with the Institutional Animal Care and Use Committee at the University of California, Davis.

Disclaimer The findings and conclusions in this article are those of the authors and do not necessarily represent the view of the U.S. Fish and Wildlife Service.

Open Access This article is licensed under a Creative Commons Attribution 4.0 International License, which permits use, sharing, adaptation, distribution and reproduction in any medium or format, as long as you give appropriate credit to the original author(s) and the source, provide a link to the Creative Commons licence, and indicate if changes were made. The images or other third party material in this article are included in the article's Creative Commons licence, unless indicated otherwise in a credit line to the material. If material is not included in the article's Creative Commons licence and your intended use is not permitted by statutory regulation or exceeds the permitted use, you will need to obtain permission directly from the copyright holder. To view a copy of this licence, visit http://creativecommons.org/licenses/by/4.0/.

\section{References}

Auld, H.L., D.L.G. Noakes, and M.A. Banks. 2019. Advancing mate choice studies in salmonids. Reviews in Fish Biology and Fisheries 29: 249-276.

Baskerville-Bridges, B., J.C. Lindberg, and S.I. Doroshov. 2005. Manual for intensive culture of delta smelt (Hypomesus transpacificus). Report to CALFED Bay-Delta Program. University of California - Davis, Davis, CA.

Bates, D., M. Mächler, B.M. Bolker, and S.C. Walker. 2015. Fitting linear mixed-effects models using lme4. Journal of Statistical Software 67: 1-48.

Bennett, W.A. 2005. Critical assessment of the delta smelt population in the San Francisco Estuary, California. San Francisco Estuary and Watershed Science 3 (2). https://doi.org/10.15447/sfews. $2005 \mathrm{v} 3$ iss 2 art 1.

Bennett, W.A., and J.R. Burau. 2015. Riders on the storm: Selective tidal movements facilitate the spawning migration of threatened delta smelt in the San Francisco Estuary. Estuaries and Coasts 38: 826-835.

Berejikian, B.A., E.P. Tezak, and A.L. LaRae. 2000. Female mate choice and spawning behaviour of Chinook salmon under experimental conditions. Journal of Fish Biology 57: 647-661.

California Department of Fish and Game. 2021. State and federally listed endangered and threatened animals of California. Retrieved from https://nrm.dfg.ca.gov/FileHandler.ashx?DocumentID= 109405\&inline. Accessed 18 November 2021.

California Natural Resources Agency. 2016. Delta smelt resiliency strategy. Retrieved from http://resources.ca.gov/docs/Delta-SmeltResiliency-Strategy-FINAL070816.pdf. Accessed 24 August 2020.

Cooke, S.J., C. Paukert, and Z. Hogan. 2012. Endangered river fish: Factors hindering conservation and restoration. Endangered Species Research 17: 179-191.

Dag, O., A. Dolgun, and N.M. Konar. 2018. Onewaytests: An R package for one-way tests in independent groups designs. The $R$ Journal 10 (1): 175-199.

Damon, L.J., S.B. Slater, R.D. Baxter, and R.W. Fujimura. 2016. Fecundity and reproductive potential of wild female delta smelt 
in the upper San Francisco Estuary, California. California Fish and Game 102 (4): 188-210.

Fleming, I.A., B. Jonsson, M.R. Gross, and A. Lamberg. 1996. An experimental study of the reproductive behaviour and success of farmed and wild Atlantic salmon (Salmo salar). Journal of Applied Ecology 33: 893-905.

Finger, A.J., B. Mahardja, K.M. Fisch, A. Benjamin, J. Lindberg, L. Ellison, T. Ghebremariam, T.-C. Hung, and B. May. 2018. A conservation hatchery population of delta smelt shows evidence of genetic adaptation to captivity after 9 generations. Journal of Heredity 109: 689-699.

Fox, J., and S. Weisberg. 2019. An R companion to applied regression, 3rd ed. Thousand Oaks, CA: SAGE Publications, Inc.

Harrison, X. A. 2015. A comparison of observation-level random effect and beta-binomial models for modelling overdispersion in binomial data in ecology and evolution. PeerJ 3: e1114.

Hirose, T., and K. Kawaguchi. 1998. Spawning ecology of Japanese surf smelt, Hypomesus pretiosus japonicus (Osmeridae), in Otsuchi Bay, northeastern Japan. Environmental Biology of Fishes 52: 213-223.

Hobbs, J.A., L.S. Lewis, M. Willmes, C. Denney, and E. Bush. 2019. Complex life histories discovered in a critically endangered fish. Scientific Reports 9: 16772.

Hung, T.-C., M. Rosales, T. Kurobe, T. Stevenson, L. Ellison, G. Tigan, M. Sandford, C. Lam, A. Schultz, and S. Teh. 2019. A pilot study of the performance of captive-reared delta smelt Hypomesus transpacificus in a semi-natural environment. Journal of Fish Biology 95: 1517-1522.

Jonsson, B., and N. Jonsson. 2006. Cultured Atlantic salmon in nature: A review of their ecology and interaction with wild fish. ICES Journal of Marine Science 63: 1162-1181.

LaCava, M., K. Fisch, M. Nagel, J.C. Lindberg, B. May, and A.J. Finger. 2015. Spawning behavior of cultured delta smelt in a conservation hatchery. North American Journal of Aquaculture 77 (3): 255-266.

Lindberg, J., R. Mager, B. Bridges, and S. Doroshov. 1997. Status of delta smelt culture project. IEP Newsletter 10 (3): 21-22.

Lindberg, J.C., G. Tigan, L. Ellison, T. Rettinghouse, M.M. Nagel, and K.M. Fisch. 2013. Aquaculture methods for a genetically managed population of endangered delta smelt. North American Journal of Aquaculture 75 (2): 186-196.

Lindberg, J.C., Y.-J.J. Tsai, B.D. Kammerer, B. Baskerville-Bridges, and T.-C. Hung. 2020. Spawning microhabitat selection in wildcaught delta smelt Hypomesus transpacificus under laboratory conditions. Estuaries and Coasts 43: 174-181.

Loosanoff, V.L. 1938. The spawning run of the Pacific surf smelt Hypomesus pretiosus [Girard]. International Review of Hydrobiology 36: 170-183.

Lura, H., and H. Sægrov. 1991. Documentation of successful spawning of escaped farmed female Atlantic salmon, Salmo salar, in Norwegian rivers. Aquaculture 98: 151-159.

Mager, R.C. 1996. Gametogenesis, reproduction and artificial propagation of delta smelt, Hypomesus transpacificus. Doctoral Dissertation, Davis, CA: University of California Davis.

Merkus, H.G. 2009. Sieves and sieving. In Particle size measurements: Fundamentals, practice, quality, 219-240. Netherlands: Springer.

Merz, J.E., S. Hamilton, P.S. Bergman, and B. Cavallo. 2011. Spatial perspective for delta smelt: A summary of contemporary survey data. California Fish and Game 97 (4): 164-189.

Moyle, P.B., B. Herbold, D.E. Stevens, and L.W. Miller. 1992. Lifehistory and status of delta smelt in the Sacramento-San Joaquin Estuary, California. Transactions of the American Fisheries Society 121 (1): 67-77.
Moyle, P.B. 2002. Inland fishes of California: Revised and expanded. Berkeley, CA: University of California Press.

Moyle, P.B., L.R. Brown, J.R. Durand, and J.A. Hobbs. 2016. Delta smelt: life history and decline of a once-abundant species in the San Francisco Estuary. San Francisco Estuary and Watershed Science 14 (2). https://doi.org/10.15447/sfews.2016v14iss2art6.

Okazaki, T., M. Miura, and H. Oohama. 2011. Spawning behavior of Wakasagi in inflowing rivers of Lake Kawaguchiko. Report of Yamanashi Prefectural Fisheries Technology Center 35: 44-59. Retrieved from https://www.pref.yamanashi.jp/suisangjt/documents/jiho38_p44-59.pdf. Accessed February 25, 2021.

Peterson, M.I., S. Kitano, and H. Ida. 2021. Resident spawning of Japanese smelt, Hypomesus nipponensis, along gravel shorelines in Lake Nojiri, Central Japan. Landscape and Ecological Engineering 17: 547-554.

R Core Team. 2018. R: a language and environment for statistical computing. R Foundation for Statistical Computing, Vienna, Austria. https://www.R-project.org/.

RStudio Team. 2018. RStudio: Integrated development environment. Boston, MA: RStudio Inc.

Schindelin, J., I. Arganda-Carreras, E. Frise, V. Kaynig, M. Longair, T. Pietzsch, S. Preibisch, C. Rueden, S. Saalfeld, B. Schmid, J.-Y. Tinevez, D.J. White, V. Hartenstein, K. Eliceiri, P. Tomancak, and A. Cardona. 2012. Fiji: An open-source platform for biological-image analysis. Nature Methods 9: 676-682.

Schneider, C.A., W.S. Rasband, and K.W. Eliceiri. 2012. NIH Image to ImageJ: 25 years of image analysis. Nature Methods 9: 671-675.

Sommer, T., F. Mejia, M. Nobriga, and L. Grimaldo. 2011. The spawning migration of delta smelt in the Upper San Francisco Estuary. San Francisco Estuary and Watershed Science 9 (2). https://doi.org/10.15447/sfews.2014v9iss2art2.

Tigan, G., W. Mulvaney, L. Ellison, A. Schultz, and T.-C. Hung. 2020. Effects of light and turbidity on feeding, growth, and survival of larval delta smelt (Hypomesus transpacificus, Actinopterygii, Osmeridae). Hydrobiologia 847: 2883-2894.

Tran, F., K. E. Berry, T.-C. Hung, E. W. Carson, W. Smith, L. T. Ellison, and S. Teh. 2019. Effects of temperature on refractory period and fecundity of delta smelt (Hypomesus transpacificus). Poster presented at: Interagency Ecological Program Annual Workshop. March 5-7, 2019. Folsom, CA.

Tsai, Y.-J.J., S. Chase, E.W. Carson, L. Zweig, and T.-C. Hung. 2021a. Characterization of spawning behavior in cultured delta smelt (Hypomesus transpacificus). North American Journal of Aquaculture 83: 51-57.

Tsai, Y.-J.J., S.N. Chase, and T.-C. Hung. 2021b. Validating the use of sodium hypochlorite for egg detachment and photograph-based egg counting in delta smelt. Aquaculture Research 52: 5936-5940.

U.S. Fish and Wildlife Service. 1993. Endangered and threatened wildlife and plants: Determination of threatened status of the delta smelt. Federal Register 58: 12854-12864.

U.S. Fish and Wildlife Service. 2019. Biological opinion: for the reinitiation of consultation on the coordinated operations of the Central Valley Project and State Water Project. U.S. Fish and Wildlife Service, 08FBTD00-2019-F-0164, Washington, D.C. Retrieved from: https://www.fws.gov/sfbaydelta/cvp-swp/documents/ 10182019_ROC_BO_final.pdf. Accessed 17 December 2020.

Venables, W.N., and B.D. Ripley. 2002. Modern applied statistics with $S, 4$ th ed. New York: Springer.

Wang, J.C.S. 2007. Spawning, early life stages, and early life histories of the osmerids found in the Sacramento-San Joaquin Delta of California. Tracy Fish Facilities Studies. Bureau of Reclamation. 38: $1-72$. 